\title{
Benefits and Drawbacks of China's Top-Down Innovation Campaign in Tertiary Science Education
}

\author{
Shihong Xu' ${ }^{1,2}$ \\ ${ }^{1}$ School of Foreign Languages, University of Electronic Science and Technology of China (UESTC), Chengdu, China \\ ${ }^{2}$ Israel Culture and Science-and-Technology Innovation Research Center, University of Electronic Science and Technology of \\ China (UESTC), Chengdu, China \\ Email:xsh303@sina.com
}

How to cite this paper: $\mathrm{Xu}, \mathrm{S}$. H. (2017) Benefits and Drawbacks of China's TopDown Innovation Campaign in Tertiary Science Education. Creative Education, 8, 55-65.

http://dx.doi.org/10.4236/ce.2017.81005

Received: December 1, 2016

Accepted: January 13, 2017

Published: January 16, 2017

Copyright $\odot 2017$ by author and Scientific Research Publishing Inc. This work is licensed under the Creative Commons Attribution International License (CC BY 4.0).

http://creativecommons.org/licenses/by/4.0/ (c) (i) Open Access

\begin{abstract}
This paper presents an analysis on China's innovative education reform in the tertiary science education from the background of a top-down innovative campaign to its purposes, reasons, effects and challenges. Under the heading of innovation and entrepreneurship education, changes happen in perspectives of educational ideology and practice, involving a wide range of policy backups, learning modes, curriculum reconstruction, teaching ability building, and entrepreneurship supervision improvement, etc. Conclusions show that the top-down innovation campaign is changing the old fabric of knowledge and skill based teaching and learning mode into a practice and innovation based teaching and learning reform. Students and teachers can enjoy a group of stimulant policies, from workload accounting of academic advisors to awarded credits for traditional courses, from scholarship recommendation and quality evaluation to postgraduate selection, from exempting learning and assessment to IE credit replacement, together with the overall arrangement of talent training. However, challenges come from curriculum reconstruction, interdisciplinary cooperation, teaching contents and pedagogy, which reflects the drawbacks of a top-down model of innovation.
\end{abstract}

\section{Keywords}

Innovation, Entrepreneurship, Science Education, Top-Down Innovative Campaign

\section{Introduction}

The beginning of the $21^{\text {st }}$ century has witnessed emergence of the conceptions of 
innovation education and innovative capability, together with a nation-level systematic and specific agenda of education innovations generated from exploratory practice of the tertiary education institutions in the past decades. Newly reports by the American Academy for the Advancement of Science (AAAS) (including Project 2061) and by the National Committee on Science Education Standards and Assessment detail goals for science education that link classroom science to practical applications and societal implications (Wikipedia, 2016). Similar strategic policies are seen in many a country of Japan, South Korea, Australia, etc. A series of educational reforms aims to increase the quality of education for talents with innovation capacities, which is taken as the core reason of developments in science and technology. As a developing country that is determined to revive its domestic strength and international influence, China is a good example to analyze benefits and drawbacks of a top-down innovation campaign that is launched from the above and requires efforts from all levels of implementation.

In China, on the day of May $13^{\text {th }}, 2015$, General Office of the State Council released to the whole society an important circular, entitled Implementation Opinions on Deepening Innovation and Entrepreneurship Education Reforms at Universities and Colleges (OPINION), announcing a practical promotion of an innovation campaign to transit China's tertiary education from a knowledgedriven tradition to an innovation-driven model (General Office of the State Council, 2015). According to OPINION, an over-round deepening of IEE reform is launched from the year of 2015, and supposed to make major advance by 2017 in perspectives of educational ideology, system construction, curriculum spreading, and entrepreneurship realization. Up to the year of 2020, an innovation-and-entrepreneurship tertiary education system is going to play roles, synthesizing scientifically classroom teaching, autonomous learning, probation and practice, supervision and assistance, and culture guidance. The expectation is that 1) the innovation-and-entrepreneurship-driven campaign will help to improve significantly the quality of talent cultivation; 2) there are salient improvements in the innovation spirit, awareness and capacity of university students; 3 ) The number of students practicing entrepreneurship increases significantly.

Obviously, this is a top-down innovation campaign launched from the top pest administrative level and supposed to bring many benefits to all levels of stakeholders from students as individuals and China as an international competitor. However, from the first day of innovation education in the last century, the tertiary education institutions as executives of the innovation campaign have encountered a lot of challenges in terms of theoretical backup, curriculum construction, and teacher resource. Science education is where the innovation campaign is particularly focused on.

The aim of this article is to give a detailed description of the innovative campaign so as to illustrate how this top-down innovation campaign is changing the old fabric of knowledge and skill based teaching and learning mode into a practice and innovation based teaching and learning reform, and to offer some sug- 
gestions for the development of educational reforms. The article is composed of 6 parts: introduction, conceptual framework, benefits for learning, curriculum system reconstruction, and drawbacks in pedagogical teaching implementation and conclusions.

\section{Conceptual Framework}

What is science education? In its broad sense science education refers to the study of phenomena and events through systematic observation and experimentation, yet in China traditionally operated in a narrow sense of educational activities merely relating to natural science education. Natural science education is composed of four perspectives: learning natural science (including integrated science) knowledge, skills, and methods; experiencing scientific exploration process and application process; enhancing understanding of relationships among science, technology and society, as well as instructing the nature of science and cultivating scientific spirit (Ma, 2007). Science education relates to 4 aspects of individual needs, social issues, employment preparation and further study (Yuan \& Cai, 2003), conventionally restricted in academic fields of spirit, acknowledge and skills. For example, "science education cultivates students' curiosity about the world and enhances scientific thinking" (Education Bureau, 2014). In the version of definition by the government of Hong Kong Special Administrative Region, students' scientific thinking is emphasized and developed through the enquiry process featured with progressive learning activities of planning, measuring, observing, analyzing data, designing and evaluation procedures, and examining evidence. This kind of definition is a typical traditional interpretation of science education, with many a confederate in the past decades, focusing more on scientific knowledge construction rather than the practical process of the knowledge application. Science education has been strongly influenced by constructivist thinking (Keith, 2009).

Based on a survey of major satisfaction from 589 undergraduates majoring in science education in four normal colleges, Zhang Dong and Xu Yinghua's investigation generates results showing that most of the students from 4 teachers colleges chose their major passively, with low degree of understanding and satisfaction. Though they have confidence in the outlook of science education, most of them don't have a plan to become science teachers in secondary schools, which is largely due to their prediction of severe employment situation of science education and drawbacks in talent training model of science education specialty (Zhang \& Xu, 2014). It is true, because in secondary education, the majority of schools and students schedule their actions by following a test-driven education while science education is much neglected for its absence in the National Entrance Examination to Colleges. Science education in secondary education is restricted to technology education. Just as Professor J. W. Geyser describes in his article of Creativity and Human Development that schools are designed to be a place where talents are appreciated and cultivated, yet the reality is not so (Geyser, 1990). It may be the right reason why China starts its innovation of 
science education from the tertiary education.

Today an innovative definition of science education is more closely connected with the innovation and entrepreneurship education (IEE), as is found in China's OPINION. According to the guidelines of OPINION, new tasks and measures for cultivating innovation capacity of talents covers a wide range of talent-cultivation-quality standard improvement, talent cultivation mechanism innovation, IEE curriculum complement, teaching pedagogy and accountability reform, IEE practice strengthening, management system innovation, IEE teaching ability building, entrepreneurship supervision improvement, and IEE funding and policy supporting, etc. As the vice-president of Tsinghua University Yang Bing says, "OPINION is not merely for a campaign to start entrepreneurship of college students, rather it concerns the academic innovation, scientific research theories, and comprehensive quality training, etc. It helps to form rational cognition and action consciousness of teaching and learning. Only by improving the quality of personnel training and promoting the comprehensive qualities of all the students can the tertiary education produce a high level of innovative entrepreneurial talents" (Deng, 2015). IEE is expected to be a sally port of education reforms in general, and science education in particular.

China's innovation reform in the tertiary science education is a top-down campaign launched from the central government. Several reasons account for the introduction of OPINION on IEE from the State Council (Xu, 2016). First, it is a hot topic of the nation to maintain its successive economic developments in terms of quality, efficiency, and upgrade. While bunches of measures and strategies are reported in many other countries to improve their innovative capacity, China responses with an innovation-driven strategy to transit its industrial structure from low-leveled manufacturing to a higher level of industrial ecology. Innovations are in urgent need to empower its core competitiveness in the international market. Second, IEE carries a hope of improving the quality of the tertiary education. As human resource is the key factor of innovation, innovation-driven economy is actually talent economy. TEI is the right place to produce labor resource and productive resource, hence undoubtedly the right place to develop innovation-based science education. Third, just as pointed out by Premier Li Keqiang in the Government Work Report of 2015, innovations can bring about enormous wisdom, motives, and opportunities to interdisciplinary and multidisciplinary cooperations, which is critical for the science and technology reform. Last but not the least, with 7.65 million graduates every year from the tertiary education institutions (Sun, 2016) and the slowing-down of economic increase, China's internal labor market is difficult to take in so many job-seekers. New positions and occupations must be explored and built to increase the employment rate. For the reasons above, the State Council publishes OPINION timely to direct and deepen the innovation and entrepreneurship education reform for science students.

The publication of OPINION has further enhanced the development of IEE by building a new conceptual framework for China's science education. It has been 
found to bring about a lot of benefits for science students in their creativity cultivation and largely change the old fabric of science education with an IEE-based curriculum construction.

\section{Benefits for Learning}

What is IEE? In China, some people think IEE means firsthand practice, but not working behind closed doors. Other people say it is capacity cultivation, rather than knowledge infusion. In an interview conducted by Zhang Suo (2015), many experts and specialists emphasize that IEE is firstly a kind of ideology and spiritual cultivation. It is in nature a kind of quality education. Quality education aims to raise learning and research ability of students. In an invited article written by Prof Sally Thomas for China Daily on November 23rd, 2011, it is recognized that "apart from improving journal quality, another way to enhance educational and academic quality, identified by policymakers, practitioners and researchers across all key policy areas including science, technology, health and education, is to develop more widely the capacity to conduct high quality research" (Thomas, 2010). IEE advocates innovation spirit in scientific research, helps to arouse entrepreneurship awareness, and expects a significant enhancement of capacity in innovation and entrepreneurship (IE). This ideology is expressed clearly in OPINION and hastens parturition of many opportunities for students' scientific practice.

A good case is reported in China Daily (Liaoning Reporter Center, 2015), entitled The Midas Touch of Northeastern University for Students' Innovation and Entrepreneurship. From the year of 2000, Northeastern University has practiced IEE by setting up IE credits, making IE capacity training plans, and building IE incentive mechanism, etc. For example, in Northeastern University, people can see a "smart" seat. It can walk on uneven terrains, automatically switching ways when up and down different stairs so as to adapt to any specification. Its own gravity support system can automatically adjust the pose of the wheelchair in the process of up and down stairs to ensure users' safety. This chair is carefully developed by a student, Gong Jiale, into so called "multi-pose intelligent stairclimbing seat", which is his 17th invention patent project. This project has been evaluated as The Best Project of Liaoning Provincial Innovation and Entrepreneurship Annual Meeting, and wins a project of Shenyang Disabled Persons Federation. In fact, Gong Jiale's project is one of the thousands of IE projects of Northeastern University.

In Northeastern University, students can gain specific IE credits for their IE practice. That these credits can substitute for relevant course credits really helps to disboard constraints from traditional courses and gain more time and energy for IE. Just as Liu Siyang, a student from Grade 2011, says: "The reason why I can put my efforts in IE activities is that the university helps to disboard the pressure of course credits and save me more free time". Liu Siyang has got 8 Science and Technology Contest prizes, 5 national patents, and has now been recommended to receive post-graduate education in Zhejiang University for his 
IE achievements.

Besides, students in Northeastern University can enjoy a group of stimulant policies, from workload accounting of academic advisors to awarded credits for traditional courses, from scholarship recommendation and quality evaluation to postgraduate selection, from exempting learning and assessment to IE credit replacement, together with the overall arrangement of talent training. Northeastern University has made constant efforts to improve relevant backup policies, making the university a dreaming place of students' IE. Students are encouraged to take part in a series of IE festivals, namely, Originality Festival for Grade One, Science Popularization Festival for Grade Two, Science and Technology Festival for Grade Three, and Entrepreneurship Festival for Grade Four. Moreover, they can experience IE in various science and technology contests, entrepreneurship pioneer class, and other activities held step by step in accordance with the developmental rules of their age. The ramparts between The First Class (academic class) and The Second Class (outclass activities) are broken through so as to achieve an organic integration of classroom teaching, science popularization activities, project training and outclass contests. Various platforms and trial flight tracks are set up for students to practice IE and gradually become developed. In recent years, students of Northeastern University have won 2545 contest prizes of provincial or above levels, carried out more than 1200 IE projects, published over 700 academic articles, gained 289 national patents, and set up dozens of student entrepreneurs, etc. In 2015, the university has particularly 1000 square meters' room for an innovation dream factory, which is the biggest supercomputer center of the northeastern part of China. Students in Northeastern Universities are benefitting from IEE with their achievements and dreams.

The same story is happening in most Chinese universities. Students can learn to develop their IE capacities with help from different governmental departments and university courses and activities. First, MOE publishes policies to initiate IEE campaigns. For example, according to MOE's Work Notice Regarding Employment And Entrepreneurship For National Ordinary University Graduates of 2016 Session $^{[12]}$, all universities are required to set up IEE courses from 2016. Students are encouraged to seek for jobs in basic level governments, in fields centering on the national development strategy, and in newly developing fields. Second, some universities have set up IEE alliances, bases and committees to guarantee an administrative agenda. Good examples are Students High-tech Business Incubator of Beijing Normal University, Haier Maker Laboratory, Innovation-Originality-Entrepreneurship Platform of Tsinghua University, National University IE Practice Center, and National IEE Alliance, etc. In these places or organizations, supports of money, information, law business, financial business, employment and risk investments are offered by universities and societal institutes. Third, a motivating atmosphere of IE is created with various level of IE contests, clubs, forums, platforms, scholarships, actual combats and colleges. Last but not the least, IEE awareness and teaching skills are embedded in curriculum instructions. For example, Beijing University has set up IEE 
courses which require integration of knowledge, teachers and students from different traditional disciplines and colleges. Teachers adopt teaching methods characterized with inspiration, discussion and participation. Students learn IE knowledge and skills from classroom lectures, expert topical forums, MOOCs and autonomous platforms. Zhejiang University has opened over 30 IEE courses, enrolled IE administration classes, applied for entrepreneurship doctorate class, held Dandelion College Student Entrepreneurship Planning Contests, and started entrepreneurship tutorial plan. All these actions bring about great opportunities for students to receive IEE and develop their IE capacities.

\section{Curriculum System Reconstruction}

Apart from ideological awareness, curriculum construction is the first step of innovation in science education. According to MOE officials' interpretation of OPINION, the practice of IEE should firstly adjust professional curriculum design according to the positioning of talent fostering and IEE goals and objectives, and how to make organic integration of professional education and IEE. By exploring and enriching IEE resources, IEE should be enhanced in the process of imparting professional knowledge and skills. The second measure is to open for all students both compulsory and selective courses of research method, academic frontier knowledge, the entrepreneur basics and employment guidance, etc. Take IEE courses into the credit system and construct IEE course groups characterized with progressive steps, organic links, scientific and rational educational ideology and methods. The third is to speed up the construction of quality IEE course informatization, open MOOCs, online video courses, and create authentication systems of online learning and credit authentication systems (Zhang, 2015a).

In the past years, some universities have already pioneered some practice deserving reference. For example, Nanjing Normal University has conducted a "triangular organization" teaching reform, dividing the under-graduation learning into three stages of Broading Training, Professional Training and Multi-element Training and 3 developmental paths of profession-academics, crossrecombination and employment-entrepreneurship. This reform offers opportunities for students to decide their own professions, courses, and developmental paths, leading to a real combination of IEE and professional education (Zhang, 2015a). In terms of IEE itself, Nanjing Normal University designs a multilevel and eurypalynous curriculum. In innovation education, it opens 182 freshman seminars, 107 high level courses for general education and 115 senior class seminars; while in entrepreneurship training it opens entrepreneur platform courses, professional courses, and flushbonading professional courses with IEE contents.

The same explorations happen in many universities and colleges, trying to break through traditional constrains and finding ways to integrate knowledge and practice. Beijing Jiaotong University has just built a 1000-square-meter IEE center for students to hold innovation and entrepreneurship activities. Student 
entrepreneurs there can obtain 10 to 50 thousand sponsorship from the university and enjoy a "green-channel" policy for the registration. About 40 thousand students in Heilongjiang Normal University have received IEE training through 8200 innovation and entrepreneurship projects, where 380 entrepreneurship teams and entrepreneurs have appeared. Tianjin Normal University has set up Student Innovation and Entrepreneurship Center, which offers a set of service to students, helping them in the whole process of "Invention-Innovation-Entrepreneurship".

In perspective of teaching pedagogy, universities are advocated to share their experimental teaching resources, set up practice and training platform, and hold entrepreneurship contest of different levels. Standard courses of KAB (Know about Business) and SYB (Start Your Business) are found to work side by side with local courses. General culture courses, professional basics, special professional knowledge, and supplementary knowledge, etc. are delivered through various practical projects. Discussion-based research methods are transformed into action-based research methods. flipped teaching and MOOCs are blooming like buds after a spring rain. All these are bringing about a new era of opportunities for students to have a full play of their learning and innovation potentials. However, to implementate an innovative curriculum, The tertiary education institutions need teaching teams with innovation ideology, awareness, and pedagogical skills as well. In other words, qualified teacher resource for IEE in science education is in urgent need. OPINION as a document can be drafted and published within days or months, yet IEE teacher resource is difficult to get ready without a long time preparation in knowledge and skills.

\section{Drawbacks in Pedagogical Implementation}

In the tertiary education, while policies can be published overnight for a nationwide campaign of IEE, teaching to develop students' IE capacities is a long-term job which actually must overcome a lot of challenges. These challenges are partly due to teaching requirements of IEE as a new way of science education. A topdown campaign is often good at its purpose and design, yet not definitely successful practice in terms of implementation in curriculum construction, team operation and teaching innovation.

Curriculum is both the carrier of teaching activities and the basic way to realize the goal of education. In IEE, curriculum construction is the core problem, for so far there is not a matured IEE curriculum formed as a system. In fact, entrepreneurship education courses and professional courses have not got integrated. Training of the entrepreneurship capacity has not been taken as part of the mainstream education system, which makes IEE disjointed with the discipline teaching and professional education. Second, in China a systematic entrepreneurship theory and practice has not yet formed. Most schools set up isolated IEE courses, not connected with other professional courses. Third, so far few unified teaching requirements and textbooks are published, due to factors such as schooling and teacher resources. Some universities and colleges open merely 
courses relating to marketing and entrepreneur running, piling up knowledge of economic management, accounting and laws in a simple way. So, it is really necessary for universities and colleges to explore a model for IEE curriculum construction (Wang, 2016).

Interdisciplinary cooperation is another problem for IEE. In universities and colleges, traditional teaching teams are formed by administrative identity or course arrangement. IEE often requires teachers from different research dimensions or course teams to work together for an advanced technology, a cross-discipline issue, or an innovative project. How and who can play a leading role in the new formed working team? How to decide the leading position of a project? How to negotiate workload within a teaching group? How will the accountability team be performed? All these and other similar questions need a coordinate department, at least, to help organize the issue from the beginning or even throughout the whole process. So far, there are few universities found to own such a coordinate department. Many universities have set up IE colleges, yet mostly some kind of virtual institute, no fixed teaching staff or administrative force.

In terms of classroom teaching, though much has been emphasized to help cultivate students' creativity ability and critical thinking ability, there are neither clear theories nor guide books telling how to teach for these two kinds of abilities. Discussions, inspirations, practices, projects are the words frequently mentioned in articles and reports to represent a student-centered teaching mode. However, teachers lack of practical ideas of how to give an IEE-driven class. Their teaching has no significant distinction with traditional course teaching. For even in the traditional courses focusing more on knowledge and skills, teaching methods has been discussed, experimented and developed all the way. Recently, some universities have held specific-post training activities and project-based learning activities to develop their teachers' own IEE awareness and teaching abilities. Also, some IE parks welcome college teachers to work there. For example, East China University of Science and Technology has published a policy to encourage teachers work together with their students or schoolmates for IE business. The motivation of this policy is that only when teachers understand how to do IE can they understand how to teach IE. Of course, this IE practice is better related to teachers' own research dimension.

As to what to teach in IEE, it seems that universities have played a role of putting the cart before the horse. IEE is not a process for successful IE examples, rather, it is for IE capacities of all students. Teachers need to tell students what IE means and what qualities and knowledge is in need for a successful IE business. Teachers should help students understand the hardship of IE and access to the facts of societal events. Students need to grasp the core of IE, rather only the skills for earning money. This situation is also reported by many scholars, such as Zhai (2015), Zhang Shiwei (Zhang, 2015b), etc., finding that many universities adopt a money-plus-tutor method to help students' IE. Some even offer working sites for IE student groups. Yet, in the whole process, few care about how the project comes into being and how it can get succeeded. Some universities even 
select projects for sponsorships only from those which are already of some scale or achievement.

To universities of coastal cities, a pervasive practice at present is opening entrepreneurship colleges. Buildings as hardware are not difficult to build, however, it is hard to find the software of guidelines for next actions. Even worse is the severe shortage of qualified teacher resource. According to incomplete statistics, the proportion between teachers and students is about 1:2000 in the field of education. This proportion actually is even smaller in IEE. IE courses are different from the ordinary model of knowledge transfer, and prefer to an experience-sharing mode. It is more important to impart and cultivate understandings of the core value in business where moral education still is the base. A traditional teacher without systematic IEE training cannot gain the qualities that an IE teacher has. That is why there is not enough IE teacher resource for most universities, not to say curriculum content, teaching modes, teaching evaluation and teaching materials or textbooks.

\section{Conclusion}

In a word, the top-down innovative campaign represented by IEE has brought many benefits to the present tertiary education in China. It is changing the old fabric of knowledge and skill based teaching and learning mode into a practice and innovation based teaching and learning reform. Students and teachers can enjoy a group of stimulant policies, from workload accounting of academic advisors to awarded credits for traditional courses, from scholarship recommendation and quality evaluation to postgraduate selection, from exempting learning and assessment to IE credit replacement, together with the overall arrangement of talent training. However, challenges come from curriculum construction, interdisciplinary cooperation, teaching contents and pedagogy, which reflects the drawbacks of a top-down model of innovation.

IEE is a worldwide campaign, government departments should behave vigorously for institutional and policy innovation, and constantly improve on a system security to guide the direction of the "public entrepreneurship and people innovation", trying to make all labor, knowledge, technology, management and capital full of gushing vitality, and give a full play to all sources of social wealth, let every business innovator has fair chance to realize their dreams.

Universities should take measures to enhance what has already achieved and make up what is in urgent need. Things as to improve talent-cultivation-quality standard improvement, talent cultivation mechanism innovation, teaching pedagogy and accountability reform, IEE teaching ability building, excellent technical personnel and welfare system are especially in need to improve the "craftsman" social status and their economic benefits so that more professionals can concentrate on their academic researches as well as teaching career for science education.

\section{References}

Deng, H. (2015). How to Five Entrepreneurship Education Classes. 
http://theory.people.com.cn/n/2015/0515/c40531-27004278.html

Education Bureau (2014). Information Exacted on 27 November 2016. http://www.edb.gov.hk/en/curriculum-development/kla/science-edu/index.html

General Office of the State Council (2015). Implementation Opinions on Deepening Innovation and Entrepreneurship Education Reforms at Universities and Colleges. Information Extracted on 27 November 2016. http://www.moe.gov.cn/jyb xxgk/moe 1777/moe 1778/201505/t20150514 188069.ht $\underline{\mathrm{ml}}$

Geyser, W. (1990). Creativity and Human Development. The International Encyclopedia of Education, 2, 496-499. Guiyang: Guizhou Education Press.

Keith S. T. (2009). Progressing Science Education: Constructing the Scientific Research Programme into the Contingent Nature of Learning Science. Berlin: Springer.

Liaoning Reporter Center of China Daily (2015). The Midas Touch of Northeastern University for Students' Innovation and Entrepreneurship. Information Extracted on 27 November 2016. http://cnews.chinadaily.com.cn/2015-05/15/content 20728792.htm

Ma, Y. (2007). On Concepts of Science Education. Information Extracted on 27 November 2016. http://chem.cersp.com/JCJX/200702/2676 4.html

Sun, M. (2016). Ministry of Human Resources and Social Security: University Graduates Are Encouraged to Find Jobs in Basic Level Governments. Information Extracted on 27 November 2016.

http://big5.gmw.cn/g2b/politics.gmw.cn/2016-07/22/content 21089323.htm

Thomas, S. (2010). The Importance of Quality Education. China Daily, 15 July 2015. Information Extracted on 27 November 2016.

http://www.chinadaily.com.cn/opinion/2010-07/15/content 10108431.htm

Wang, Q. (2016). Thinking Education: Layouts of Innovation and Entrepreneurship Education at Colleges and Universities. Xinhua Education. Information Extracted on 27 November 2016. http://education.news.cn/2016-01/06/c 128600836.htm

Wikipedia (2016). https://en.wikipedia.org/wiki/Science education

$\mathrm{Xu}, \mathrm{S}$. (2016). An Innovative Campaign Is Changing the Fabric of Chinese Science Education: Opportunities and Challenges. In 2016 the International Conference on Economic Science and Management Engineering.

Yuan, Y, \& Cai, T. (2003). Science Curriculum and Pedagogy. Huangzhou: Zhejiang Education Press.

Zhai, J. (2015). The Misunderstandings of Entrepreneurship Education in Colleges and Universities and Suggestions. Journal of Hebei Energy Institute of Vocation and Technology, 4, 7-9.

Zhang, D., \& Xu, Y. (2014). The Survey of Major Satisfaction of Science Education Specialty for Undergraduates. Journal of Chongqing Normal University (Natural Science), $6,145-149$.

Zhang, S. (2015a). How to Teach Innovation and Entrepreneurship in Colleges and Universities. Information. People's Daily, 15 July 2015.

Zhang, S. (2015b). Difficulties, Causes and Solutions of Entrepreneurship Education of Local Universities in the New Normal. Theory and Practice of Education, 11, 6-8. 
Submit or recommend next manuscript to SCIRP and we will provide best service for you:

Accepting pre-submission inquiries through Email, Facebook, LinkedIn, Twitter, etc. A wide selection of journals (inclusive of 9 subjects, more than 200 journals)

Providing 24-hour high-quality service

User-friendly online submission system

Fair and swift peer-review system

Efficient typesetting and proofreading procedure

Display of the result of downloads and visits, as well as the number of cited articles Maximum dissemination of your research work

Submit your manuscript at: http://papersubmission.scirp.org/

Or contact ce@scirp.org 